\title{
Two Rare Anatomical Variations of External Jugular Vein - an Embryological Overview
}

\author{
Dos Raras Variaciones Anatómicas de la Vena Yugular Externa - una Visión Embriológica
}

"Susmita Ghosh; "Lopamudra Mandal; " Sanchita Roy \& ${ }^{* * *}$ Manimay Bandyopadhyay

GHOSH, S.; MANDAL, L.; ROY, S. \& BANDYOPADHYAY, M. Two rare anatomical variations of external jugular vein - an embryological overview. Int. J. Morphol., 30(3):821-824, 2012.

SUMMARY: Human anatomy is an ocean of unending variations and its mysteries are being unravelled since ages. Knowledge of variations in the superficial veins of head and neck is essential to carry out successful surgical procedures. During routine dissection of head and neck of two middle aged male cadavers, in the Department of Anatomy, Calcutta National Medical College, Kolkata, India, we came out with some interesting venous architecture. The retromandibular vein on the left side of both the cadavers was found to be undivided and joined with the facial vein in the neck at an acute angle to form a common venous trunk at variable distances from the angle of the mandible. That trunk ultimately drained into the left subclavian vein. This might be the result of disappearance of the cephalic part of the external jugular vein and formation of an additional communication between common facial vein and the external jugular vein in foetal life. In one case, we also came across an extra transverse communication between that common trunk and the internal jugular vein. A detail of those cases with embryological explanation is attempted.

KEY WORDS: External jugular vein; Retromandibular vein; Facial vein; Variation, communication.

\section{INTRODUCTION}

Maxillary and superficial temporal veins unite within the substance of parotid gland to form the retromandibular vein (RMV) which soon divides into anterior and posterior divisions. Anterior division unites with facial vein (FV) at variable distances below the angle of the mandible to form the common facial vein (CFV) which ends by draining into the internal jugular vein (IJV). The posterior division of RMV unites with the posterior auricular vein (PAV) to form external jugular (EJV) vein which runs down the neck to drain into the subclavian vein (SV) (Standring, 2005). There is wide variation in the formation and termination of the EJV. According to Choudhury et al. (1997) in 5\% cases FV ultimately drains into EJV. In one case, reported by Prakash \& Bhagath (2007), CFV on the left side drained directly into the SV. EJV is superficially visible and easily approachable and so is used very frequently for intra venous cannulation for diagnostic and therapeutic purposes (Prakash et al., 2006). We present here, two rare variations of EJV in regards to its formation, course, termination and communication.

\section{CASES REPORT}

While carrying out routine dissection on intact formaldehyde preserved cadavers for undergraduate teaching in Calcutta National Medical College, Kolkata, India, we found two rare patterns in the architecture of the superficial veins of neck.

CASE 1. An undivided RMV came out from the left parotid gland. It received PAV on its posterior aspect. The FV after receiving the submental vein from the submental region joined the RMV at an acute angle on its anterior aspect, $4 \mathrm{~cm}$ below the angle of the mandible. The common trunk thus formed runs downwards for $10 \mathrm{~cm}$ in front of the anterior margin of the sternocleidomastoid muscle, to drain into same sided SV. Interestingly, this common venous trunk had a single transverse communication ( $2 \mathrm{~cm}$ long, $0.8 \mathrm{~cm}$ thick) with the same sided IJV. The communication was found 9.5 $\mathrm{cm}$ above the sternal end of the clavicle. On the right side, the pattern was a classical one.

\footnotetext{
* Assistant Prof, Calcutta National Medical College, 32, Gorachand Road, Kolkata-700014, India.

** Assistant Prof. Institute of Post Graduate Education \& Research, 244, A J C Bose Road, Kolkata -700020, India.

**** Prof. Medical College, Kolkata, 88,College Street, Kolkata -700073, India.
} 
CASE 2. From parotid gland on the left side the trunk of RMV came out without division. While within the gland the trunk received the PAV from behind. The FV after crossing the lower margin of the body of the mandible, moved downwards obliquely to meet the undivided RMV in the lower part of the neck $8.2 \mathrm{~cm}$ below the angle of the mandible. The common trunk thus formed, ran for $3 \mathrm{~cm}$, and crossed the sternocleidomastoid muscle superficially from before backwards, finally terminating in the same sided SV. The formation and the termination of the EJV on the right side was as per the classical pattern.

\section{DISCUSSION}

Variations regarding FV, RMV and EJV have been studied by many workers. Nayak \& Soumya (2008) described a case where EJV was formed by the union of FV and undivided RMV where the PAV was absent and EJV had a communication with cephalic vein. Choudhary et al. (2010) presented a case where bilaterally undivided

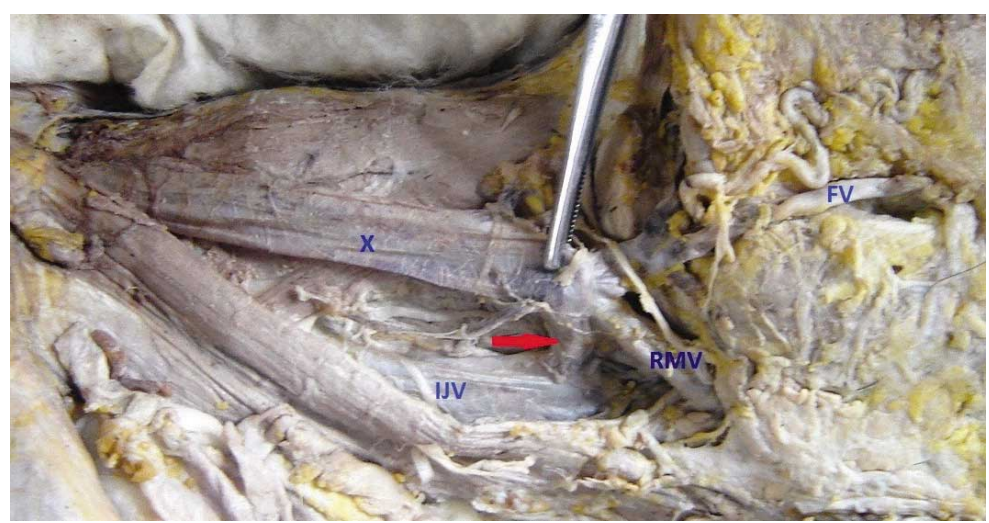

Fig 1. RMV- retromandibular vein, FV-facial vein, IJV-internal jugular vein, $\mathrm{X}$-common venous trunk formed by the union of RMV \& FV. Red arrow indicates the communication between X \& IJV.

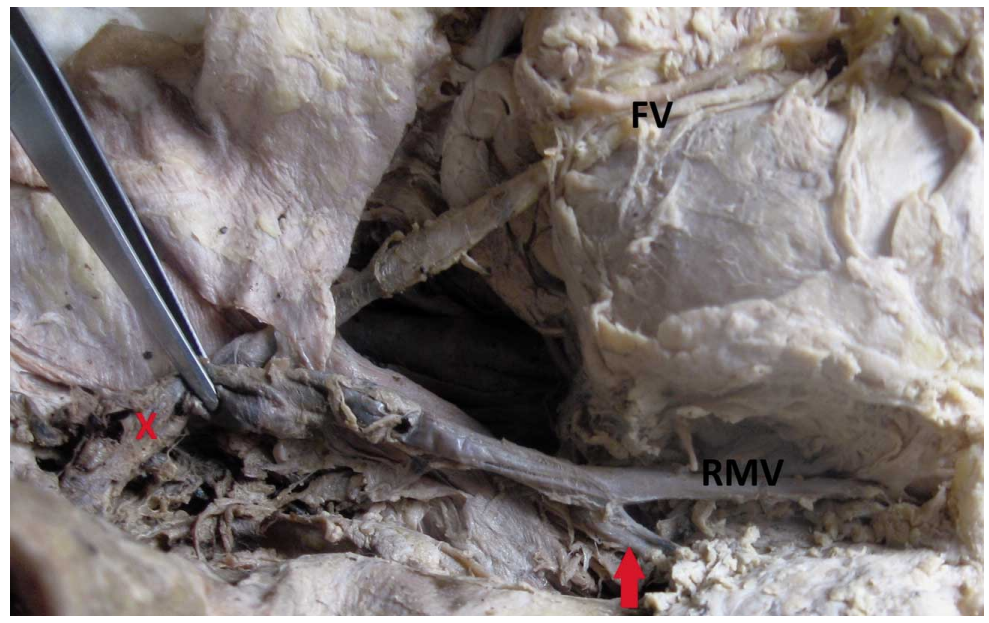

Fig. 2. RMV- retromandibular vein, FV-facial vein, X-common venous trunk formed by the union of RMV \& FV. Red arrow indicates posterior auricular vein.
RMV continued as EJV after receiving PAV and FV obliquely. On the contrast, Bertha \& Suganthy (2011) while studying variation of $\mathrm{FV}$ at its termination described a case where bilaterally, undivided RMV joined with FV to form a common trunk, which in turn drained into same sided SV. He termed this common trunk as CFV and considered EJV to be absent. Above mentioned studies indicate that the common trunk formed by the union of undivided RMV and FV had been termed as CFV by some and EJV by others. As per Choudhury et al., the point of drainage of FV into EJV varied between 55-104 $\mathrm{mm}$ from the angle of the mandible. In the two cases we dissected, the length of the common trunk formed by the union of the undivided RMV and the facial vein took place at two different levels, $40 \mathrm{~mm}$ and $82 \mathrm{~mm}$ respectively below the angle of mandible. The course of the common trunk also differed in those cases. In case 1 , it was in the anterior triangle, and then ran under the anterior margin of sternocleidomastoid muscle near the termination whereas in case 2 the formation was much lower and was on the muscle throughout. Thus, these cases throw light on the wide variation of the level of formation \& course of the common trunk. After considering the developmental aspect of these veins, we prefer to call this common trunk as EJV. In the case 1 , there was a communication between the EJV and IJV and in that particular case, the level of formation is $40 \mathrm{~mm}$ below the level of the angle of the mandible. This is explainable on developmental grounds. Even after extensive search, mention of such communication has not been found in any previous literature. Such communication if transverse and of considerable length as in this case is likely to interfere with any surgical intervention in the neck. IJV being the major venous channel draining the interior of the cranium, its communication with the EJV might act as a collateral channel as well as a route of spread of infection from the neck and face to the brain. EJV is one of the common sites chosen for central venous catheterisation. Even while doing IJV cannulation by the posterior approach, EJV should be located first (Griffin \& Topol, 2009). To prevent venous injury, knowledge of such variation is essential for the clinicians performing these manoeuvres. 


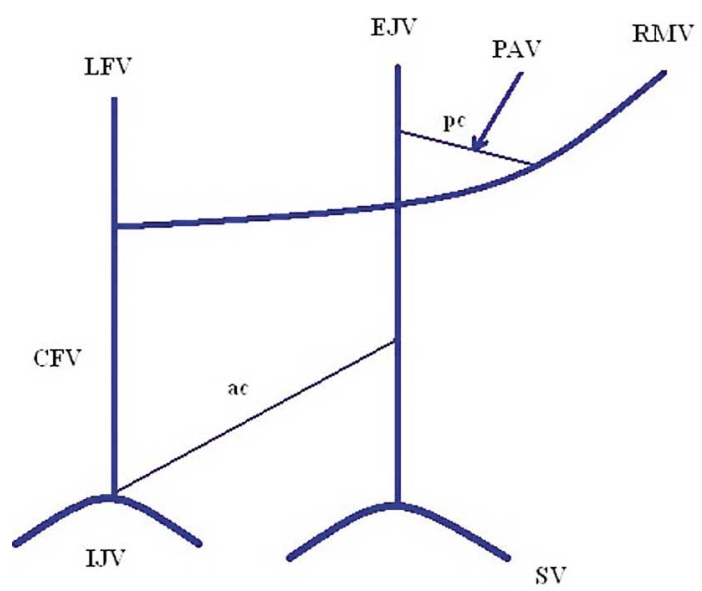

Fig. 3. Schematic representation of superficial venous pattern of neck in early stages of development. LFV linguofacial vein, CFV -common facial vein, IJV internal jugular vein, EJV -external jugular vein, SV subclavian vein, RMV -retromandibular vein, PAV posterior auricular vein, ac-anterior communication of EJV, pc-posterior communication of EJV.

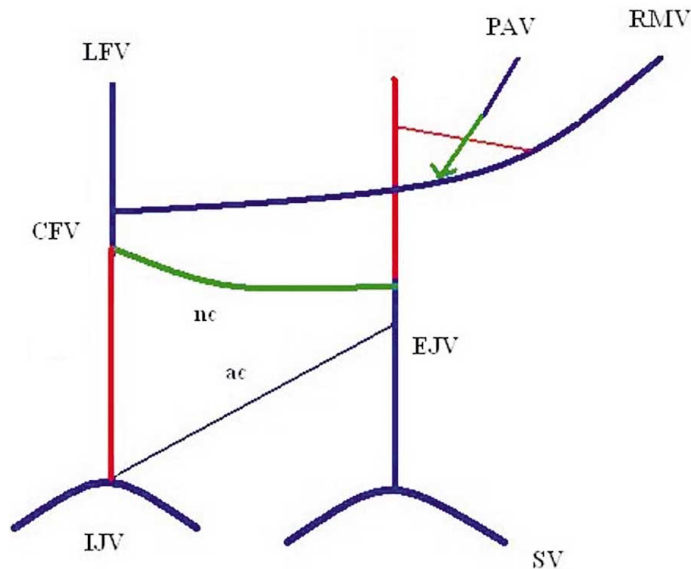

Fig. 4. Schematic representation of embryological basis of venous variation in case 1 . Blue lines indicate remaining initial pattern, Red lines indicate obliterated segments of initial pattern, Green lines indicate added modifications to initial pattern, $\mathrm{nc}$-new communication between CFV and EJV.

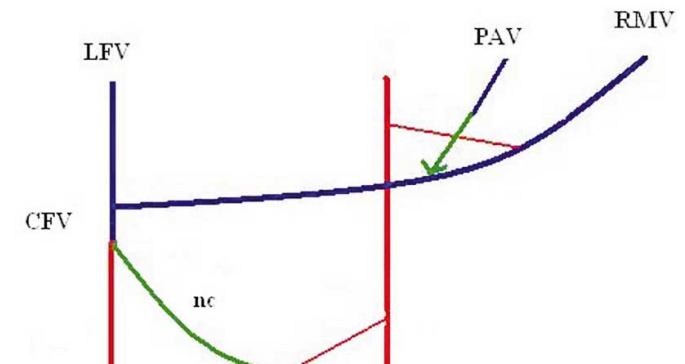

Hence as per Prakash et al., ultrasound guided venepuncture is a better alternative to prevent those complications. Its knowledge is also essential for the surgeons while doing reconstructive surgeries of the face and neck and radical neck dissection.

Embryological explanation. Development of the veins of head \& neck are only apparent after the development of skull. First to develop is the ventral pharyngeal vein, which opens into the precardinal vein (the future IJV). Gradually the ventral pharyngeal vein receives a tributary from face and tongue - known as linguofacial vein. At $18 \mathrm{~mm}$ stage of the embryo, a considerable large vein - known as RMV develops which drains venous blood from the temporal region into the linguo facial vein. The common trunk thus formed is known as CFV which normally drains into the precardinal vein (Fig.3). The pre axial vein of the upper limb (future cephalic vein) receives a tributary, EJV, which drains tissues of neck. The definitive EJV ultimately drains into the SV (Standring). EJV communicates in front (ac in Fig 3) with terminal part of the developing common facial vein or into the precardinal vein and posteriorly (pc in Fig 3) with the RMV. PAV opens in the posterior communication which later on appears to be the posterior division of the RMV. Linguo facial vein later on becomes facial vein. In later life we find that, posterior division of RMV unites with PAV to form EJV. The initially formed RMV now serves as the anterior division of future RMV, this after uniting with the FV, leads to formation of CFV (Fig. 3). Sometimes, in early developmental stages, cephalic part of EJV may disappear (Bertha \& Suganthy). Then an extra communication (nc in Figs. 4 \& 5) arises between CFV and caudal part of EJV. Also, due to degeneration of cephalic part of EJV, there is no posterior communication with RMV, and PAV has to open in the undivided RMV (Figs. 4 \& 5). Thus, in cases where cephalic part of EJV disappears early, final pathway of venous drainage is as follows: undivided RMV $\rightarrow$ joins with FV $\rightarrow \mathrm{CFV} \rightarrow$ opens into caudal part of EJV (segment of CFV draining into precardinal or IJV disappears) via the extra communication (nc in Figs. 4 \& 5) $\rightarrow$ SV. This embryologically explains the superficial venous architecture of neck in both cases 1 and 2. In case 1 there is an additional finding of a transverse communication between IJV and EJV. The anterior communication (ac in Figs. 3 and 4) from EJV to developing CFV or precardinal vein if persists, will lead to the above variation. Persistence of such communication is again more probable when only a short cephalic segment of EJV degenerates and a longer stretch of EJV remains caudally as in case 1. Thus, association of longer EJV with persistence of communication between EJV and IJV can be explained embryologically (Fig. 4). In cases with a short EJV, there is lesser possibility of such communication as a large cephalic part has already degenerated (Fig. 5).

Fig. 5. Schematic representation of embryological basis of venous variation in case2, Blue lines indicate remaining initial pattern, Red lines indicate obliterated segments of initial pattern, Green lines indicate added modifications to initial pattern, nc -new communication between CFV and EJV. 
GHOSH, S.; MANDAL, L.; ROY, S. \& BANDYOPADHYAY, M. Dos raras variaciones anatómicas de la vena yugular externa - una visión general embriológica. Int. J. Morphol., 30(3):821-824, 2012.

RESUMEN: La anatomía humana tiene un sin fin de variaciones y sus misterios se han develado desde el inicio de los tiempos. El conocimiento de las variaciones anatómicas de las venas superficiales de la cabeza y del cuello es fundamental para llevar a cabo con éxito los procedimientos quirúrgicos. Durante una disección de rutina de cabeza y cuello encontramos una arquitectura venosa interesante en dos cadáveres de hombres de mediana edad en el Departamento de Anatomía de la Facultad de Medicina Nacional Calcuta, Calcuta, India. En el lado izquierdo del cuello de ambos cadáveres, la vena retromandibular no se encontraba dividida, y se unía a la vena facial en un ángulo agudo, para formar un tronco venoso común a una distancia variable desde el ángulo de la mandíbula. Ese tronco finalmente drenaba en la vena subclavia izquierda. Esto podría ser el resultado de la desaparición de la parte cefálica de la vena yugular externa y la formación de una comunicación adicional entre la vena facial común y la vena yugular externa en la vida fetal. En un caso, también se encontró con una comunicación adicional transversal entre ese tronco común y la vena yugular interna. Se realiza una descripción en detalle de los casos junto a una explicación embriológica.

PALABRAS CLAVE: Vena yugular externa; Vena retromandibular; Vena facial; Variación; Comunicación.

\section{REFERENCES}

Bertha, A. \& Suganthy, R. Anatomical Variations in Termination of Common facial Vein. J. Clin. Diagn. Res., 5(1):24-7, 2011.

Choudhary, S.; Sharma, A. K. \& Singh, H. Undivided retromandibular vein continuing as external jugular vein with facial vein draining into it : an anatomical variation. $J K$ Science, 12(4):203-4, 2010.

Choudhury, R.; Tuli, A. \& Choudhury, S. Facial vein terminating in the external jugular vein an embryologic interpretation. Surg. Radiol. Anat., 19(2):73-7, 1997.

Griffin, B. P. \& Topol, E. J. Manual of cardiovascular Medicine. 3rd Ed. Philadelphia, Lippincott Williams \& Wilkins, 2009. pp.744-6.

Nayak, S. \& Soumya, K.V. Abnormal formation and communication of external jugular vein. Int. J. Anat. Var., 1:156, 2008 .

Prakash, B. B. \& Bhagath, K. P. A rare termination of left common facial vein into left subclavian vein. a case report. Int. J. Morphol., 25(3):555-6, 2007.

Prakash, R.; Prabhu, L. V.; Kumar, J.; Nayak, V. \& Singh, G. Variations of jugular veins: phylogenic correlation and clinical implications. South Med. J., 99(10):1146-7, 2006.

Standring, S. M. Grays Anatomy. 39 ${ }^{\text {th }}$ Ed. London, Elsevier Churchill Livingstone, 2005. p.551-2, 618.

\author{
Correspondence to: \\ Dr.Susmita Ghosh \\ P-14, DR. A. K. Paul Road Extension \\ Behala, Kolkata \\ West Bengal \\ Pin: 700034 \\ INDIA
}

Phone (91)9433205287(M)

Fax (91)03322843582

Email: drsusmita2077@gmail.com

Received: 23-08-2011

Accepted: 01-03-2012 